\title{
One veil less for Japanese science
}

Will the Japanese science bureaucracy's drive to end oriental inscrutability serve simply to whet Western appetites for more information?

OBSERVANT readers may have noticed that news of the Japanese government's budget requests for science and technology (see page 783) are being published in Nature a week or two earlier than usual. That may not seem a remarkable change but it is in fact an indicator of new and welcome efforts by several of Japan's science-related ministries and agencies to communicate more effectively with the outside world.

Budget requests are normally released to the Japanese press at the end of August and until that time government officials would never grant interviews on the requests of the foreign press (unless they had some pet project they wanted to promote). But last Friday, nearly a week before the budget requests were to be officially submitted to the Ministry of Finance, the Agency of Industrial Science and Technology (AIST) of the Ministry of International Trade and Industry (MITI) put on a seven-hour series of lectures by 13 heads of department on AIST's budget requests. A similar meeting was held by the Science and Technology Agency (STA) on Monday. The language of the meetings was primarily English, which was a mark of the generosity of the Japanese participants, although that matters less than that the meetings took place. For anyone familiar with the well-oiled public relations operations of government in Washington, DC, for example, this may not seem particularly unusual. But in Japan such willingness to open the machinery of government to foreigners is unprecedented.

MITI and STA may be rightfully proud of what they have done. Other of Japan's science-related ministries will now be put in a position of having to follow suit or seeming hopelessly parochial. Even the highly conservative Ministry of Education, Science and Culture (MESC) shows signs of welcoming foreign interest. Earlier this month the ministry proudly presented the foreign press with descriptions in English of the ministry's awards of "special distinguished" grants - a welcome move but one nevertheless long overdue given that the grants are intended to be for "internationally recognized research."

The reasons for the Japanese government's interest in the foreign science press are not hard to fathom. In the case of MITI, some people within the ministry have argued for the past several years that all of its major research projects should be opened to participation by foreign researchers and by foreign companies. Once this became the consensus view and passed into official policy NATURE $\cdot$ VOL $346 \cdot 30$ AUGUST 1990 in June, MITI officials realized that if they did not explain their projects to the Western world then their new policy would have been established in vain.

The more interesting question is what will happen next. The new policy strips away one of the veils that surround decision-making in the Japanese government and will help the Western world to receive some early warning of new initiatives in science and technology. But in important ways, Japan remains quite different from its chief competitor in the West.

In the United States, numerous organizations that are independent of government help to assess and decide national policy, among the more influential being the National Academy of Sciences and the congressional Office of Technology Assessment. The results of their deliberations are prepared for public distribution. These relatively transparent organizations have no equivalents in Japan, where enigma still surrounds the deliberations which gives birth to a government budget request. MITI, STA (and other organizations which jump on their bandwagon) must expect that having seen one veil removed, foreigners will hope that others will soon follow.

\section{Reactor woes}

Berlin's Hahn-Meitner Institute is in danger. West German researchers could be doing more to save it.

RESEARCHERS in West Germany should stand up for the embattled Hahn-Meitner Institute, now in danger of being shut down as a result of the West Berlin city government's refusal to license a newly renovated reactor upon which the institute depends for its research. The Hahn-Meitner Institute, which is one of 13 national laboratories, may not be able to survive if the reactor is not licensed soon (see Nature 346, 688).

On the face of it, the battle for the Hahn-Meitner Institute has little to do with research and much to do with the antipathy to nuclear power that is prevalent in West Germany. Opponents of nuclear power in West Berlin, which actually has no nuclear-power reactors of its own, have simply latched onto the institute as a convenient target for a crusade against nuclear energy. Their argument - that a government must offer an adequate storage site for nuclear waste before it grants an operating 